\title{
Dietary patterns and benign breast diseases: a case-control study
}

\author{
Zeinab Tiznobeyk ${ }^{1}$, Zahra Sheikhi Mobarakeh ${ }^{2 *}$, Mostafa Qorbani ${ }^{3}$, Fariba Koohdani ${ }^{4}$, Gity Sotoudeh ${ }^{1 *}$, \\ Farahnaz Khajehnasiri ${ }^{5}$, Shahla Khosravi ${ }^{5}$ and Farideh Doostan ${ }^{6}$ \\ ${ }^{1}$ Department of Community Nutrition, School of Nutritional Sciences and Dietetics, Tehran University of Medical Sciences, \\ Hojatdost Street, Naderi Street, Keshavarz Boulevard, Tehran 14155/6117, Iran \\ ${ }^{2}$ Department of Cancer Quality of Life, Breast Cancer Research Center, Academic Center for Education, Culture and Research \\ (ACECR), 146, South Gandi Avenue, Vanak Square, Tebran 1517964311, Iran \\ ${ }^{3}$ Department of Community Medicine, Alborz University of Medical Sciences, Taleghani Square, Taleghani Boulevard, Edari \\ Shahrak, Karaj 3146883411, Iran \\ ${ }^{4}$ Department of Cellular, Molecular Nutrition, School of Nutritional Sciences and Dietetics, Tehran University of Medical \\ Sciences, Hojatdost Street, Naderi Street, Keshavarz Boulelvard, Tehran 14155/6117, Iran \\ ${ }^{5}$ Department of Social Medicine, School of Medicine, Tebran University of Medical Sciences, Qods Street, Poorsina Street, \\ Tehran 14155/6134, Iran \\ ${ }^{6}$ Department of Nutrition, School of Health, Kerman University of Medical Sciences, Jomboori Eslami Boulevard, Kerman \\ 7616913555, Iran
}

(Submitted 4 March 2016 - Final revision received 10 April 2016 - Accepted 15 April 2016)

\section{Abstract}

Several studies have investigated the relation between benign breast diseases (BBD) and food intake. However, dietary patterns of these patients have not been taken into consideration up to now. The aim of this study is to determine the association between dietary patterns and BBD. In this case-control study, ninety-six patients with BBD and seventy controls were selected from women attending the Iranian Center for Breast Cancer affiliated with Academic Center for Education, Culture and Research. Demographic, physical activity and semi-quantitative FFQ were completed. The main dietary patterns were extracted by factor analysis. Two major dietary patterns emerged: Healthy dietary pattern including fish, poultry, eggs, low-fat dairy products, vegetables, legumes, nuts and seeds, whole grains, oil and mayonnaise, olives, fruits; and Unhealthy dietary pattern including red meats, organ and processed meats, high-fat dairy products, refined grains, sweets and desserts, animal and solid fats. After adjustment for age, BMI and energy intake, the participants in the highest tertile of Healthy dietary pattern (OR 0.44 ; $95 \%$ CI 0.20, 0.99) were less likely to have BBD compared with those in the first tertile. After adjustment for other confounding variables, this relationship still remained close to significant level. However, higher consumption of Unhealthy dietary pattern was not associated with the risk of BBD. In conclusion, Healthy dietary pattern might be inversely associated with the risk of BBD; however, this result should be interpreted with caution. Future studies are needed to confirm our findings.

Key words: Benign breast diseases: Dietary patterns: Case-control studies

The term 'benign breast diseases' (BBD) is applied to describe a wide range of non-cancerous breast diseases. These diseases are classified into three groups based on their influence on breast cancer risk: (1) non-proliferative diseases, which are not associated with breast cancer risk; (2) proliferative diseases without atypia, which stimulate the growth of lobular and ductal cells in breast tissue ${ }^{(1)}$ and which increase the breast cancer risk by 1.3-1.9 times $^{(2)}$; and (3) proliferative diseases with atypia such as atypical ductal and lobular hyperplasia ${ }^{(1)}$. The risk of breast cancer is 3.7-4.2 times higher in the third group ${ }^{(2)}$. Although BBD cases constitute $>90 \%$ of reasons for attending breast clinics ${ }^{(3)}$, these diseases are usually disregarded in comparison with breast cancer ${ }^{(4)}$. In autopsy studies, it is estimated that one in two women will be diagnosed with some grades of cystic fibrosis, and one in five will suffer from fibroadenoma in their lifetime. The role of endogenous hormones, oral contraceptive and oestrogen replacement therapy in the development of BBD entails further investigation. Obesity is established as the sole protective factor, although it is not recommended because of adverse effects. No relationship has been established between the age at menarche, smoking, alcoholic drinks and caffeine consumption with $\mathrm{BBD}^{(5)}$. Several

Abbreviation: BBD, benign breast diseases.

* Corresponding author: G. Sotoudeh, fax +98 218897 4462, email gsotodeh@tums.ac.ir; Z. Sheikhi Mobarakeh, fax +98 21 8879 6208, email dr.shaikhi88@ yahoo.com 
studies have been undertaken to assess the association between food, macronutrients and micronutrients with the risk of $\mathrm{BBD}^{(5-17)}$. Regarding the association of food intake and BBD, some controversial results are reported and no specific dietary pattern has been yet proposed ${ }^{(5)}$. Ingram et $a{ }^{(10)}$ found the consumption of red meats, savoury dishes (pizza, pie and stew) and starches to be harmful, whereas eating poultry, fish and fruits is beneficial. Fruits and vegetables are suggested to protect against $\mathrm{BBD}^{(8,9,16)}$. In the Women's Health Initiative (WHI) trial, a low-fat dietary pattern with reduced fat intake and increased fruit and vegetable consumption did not alter the progression of $\mathrm{BBD}^{(15)}$. The dietary patterns have grabbed the attention of researchers during the past decade ${ }^{(18,19)}$, because of the involvement of the interactions of dietary components and synergic effects of food ingredients ${ }^{(20-23)}$. The use of dietary patterns could better reflect the nutritional behaviour in individuals ${ }^{(24,25)}$. Moreover, dietary patterns are more appropriate tools for public health nutrition recommendations ${ }^{(20,22,23,25)}$. So far, no study has evaluated the relationship between the dietary patterns and BBD morbidity. Because of the high prevalence of these disorders in women ${ }^{(5)}$ and the risk of cancer development among them ${ }^{(2)}$, we aimed to investigate the relationship between dietary patterns and BBD.

\section{Methods \\ Study population}

The present study is part of a case-control research project on women diagnosed with breast cancer and BBD, as well as healthy individuals attending the Iranian Center for Breast Cancer affiliated with Academic Center for Education, Culture and Research (ACECR) in Tehran, from February 2014 to April 2015. The aim of the project was to compare the dietary patterns of patients with breast cancer and BBD with healthy women.

The sample size was calculated using an $\alpha$ of 0.05 and a power of $80 \%$, detecting a minimum significant outcome measure OR of 2.5. About eighty subjects were estimated for each of the three groups, and in practice eighty patients with breast cancer, ninetysix patients with BBD and seventy healthy women were recruited. As healthy subjects were not easily available, for maintaining the power of study, we increased the number of BBD patients to ninety-six. In the present study, we compared the dietary patterns in two groups of BBD patients and healthy women.

The cases were older than 20 years, diagnosed with BBD (including fibrocystic diseases, ductal ectasia, fat necrosis, papillomatosis, adenosis with and without sclerosing, fibroadenoma, ductal hyperplasia, atypical lobular hyperplasia and atypical ductal hyperplasia) by the physicians of ACECR within the past 1 month. The controls were selected from women who accompanied patients or those who attended ACECR for check-up, and were diagnosed as healthy by the physicians, without any symptoms or complaints for BBD. We excluded individuals with $\mathrm{BMI} \geq 40 \mathrm{~kg} / \mathrm{m}^{2}$, history of diagnosis with CVD, diabetes, hypertension, dyslipidaemia, renal diseases, liver or gastrointestinal diseases, food allergy, stroke, fibromyalgia, multiple sclerosis, Parkinson's disease, current alcoholism or drug addiction, as well as self-reported withdrawal in the past 3 months, current pregnancy or lactation in the past 12 months. In total, ninety-six patients with BBD, aged $20-70$ years, were selected as the case group and seventy non-diseased healthy individuals were selected as the control group using convenience sampling. The controls were healthy subjects who were visiting the centre for routine screening. By using frequency matching, the two groups were matched for age (age groups of 10 years) and menopause status.

\section{Socio-demographic and lifestyle characteristics}

Individual-specific information was collected via face-to-face interviews. Individual characteristics including age, residence status, educational level, job status, marital status, age at menarche, age at first full-term pregnancy, number of pregnancies, history of lactation, menopause status, history of oral contraceptive use and oestrogen therapy, family history of breast diseases, cigarette, hubble-bubble and tobacco-pipe smoking, vitamin and mineral supplement intake were recorded.

\section{Anthropometric and physical activity measures}

Weight was measured to the nearest $100 \mathrm{~g}$ with light clothing and without shoes using a weighing scale (Seca:813; Seca United Kingdom), and height was measured using a non-elastic measuring tape to the nearest $1 \mathrm{~mm}$ without shoes, heels together touching the wall and looking straight forward. BMI was calculated by dividing weight in kilograms by height in metres squared. Waist circumference (WC) was measured at a level midway between the lower rib margin and the iliac crest at the end of a gentle expiration and at standing position using a tape to the nearest $1 \mathrm{~mm}$. In order to eliminate individual errors, the height, weight and WC were measured only by the first researcher.

International Physical Activity Questionnaire-short form was used to assess the level of physical activity of the participants ${ }^{(26)}$. Individuals were asked about the frequency (d) and duration (min) of severe, moderate, jogging and sedentary physical activity during the past $7 \mathrm{~d}$. To gain basic scoring, individuals must have at least $10 \mathrm{~min}$ of continuous physical activity. Physical activity score was calculated as metabolic equivalent task per minute per week (MET-min/week) for severe, moderate and jogging activities. The score of engaging in different levels of activity over the past week is calculated by multiplying the frequency of days by duration of time ( $\mathrm{min}$ ), as well as by constants of 8,4 and $3 \cdot 3$, respectively. Finally, the sum of three scores was calculated as total exercise per week (total MET-min/week).

\section{Dietary intake assessment}

Usual dietary intake of individuals during the past year was assessed using a valid and reliable semi-quantitative FFQ from Tehran Lipid and Glucose Study ${ }^{(27)}$. This 168-food-item questionnaire was completed via face-to-face interview by a trained dietitian. Dietary intake of six food groups including breads and cereals, meats, dairy products, vegetables, fruits and miscellaneous foods was assessed. Participants were asked to report the frequency of consumption for each food item in 
Table 1. Food grouping used in factor analysis

\begin{tabular}{|c|c|}
\hline Groups & Subgroups \\
\hline $\begin{array}{l}\text { Red, organ meats and } \\
\text { processed meat }\end{array}$ & $\begin{array}{l}\text { Beef, lamb, ground meat, liver, heart, kidney, } \\
\text { hamburger, sausage, kielbasa }\end{array}$ \\
\hline Fish & Fish, canned fish \\
\hline Poultry & Chicken \\
\hline Eggs & Eggs \\
\hline Low-fat dairy products & $\begin{array}{l}\text { Low-fat milk, low-fat yogurt, cheese, Doogh } \\
\text { (an Iranian yogurt drink) }\end{array}$ \\
\hline High-fat dairy products & $\begin{array}{l}\text { High-fat milk, cocoa milk, yogurt, cheese, } \\
\text { ice cream, dried whey, cream }\end{array}$ \\
\hline Tea and coffee & Tea, coffee \\
\hline Cabbage & Cabbage \\
\hline Green leafy vegetables & Spinach, lettuce \\
\hline $\begin{array}{l}\text { Orange and red } \\
\text { vegetables }\end{array}$ & $\begin{array}{l}\text { Carrot, tomato, tomato paste and ketchup } \\
\text { sauce }\end{array}$ \\
\hline Other vegetables & $\begin{array}{l}\text { Eggplant, celery, cucumber, pea, string bean, } \\
\text { garlic, onion, pepper, mushroom, turnip, } \\
\text { local vegetables, etc. }\end{array}$ \\
\hline Cooked potato & Baked potato \\
\hline French fries & French fries \\
\hline Whole grains & Maize, barley, whole bread \\
\hline Refined grains & $\begin{array}{l}\text { White breads, baguettes, rice, spaghetti, } \\
\text { vermicelli }\end{array}$ \\
\hline Salted snacks & Chips, cheese puff, cracker \\
\hline Olive & Olive oil, olives \\
\hline Sweets and desserts & Biscuit, cake, cookie, halva (an Iranian sweet) \\
\hline Pickles & Pickles (in vinegar or brine) \\
\hline Hydrogenated oil & Butter, margarine, solid fat, animal fat \\
\hline $\begin{array}{l}\text { Vegetable oil and } \\
\text { mayonnaise }\end{array}$ & Vegetable oils, mayonnaise \\
\hline Fruit and fruit juice & $\begin{array}{l}\text { Dried fruit, fruit juice, canned fruit, cantaloupe, } \\
\text { melon, watermelon, pear, apricot, cherry, } \\
\text { apple, peach, fig, grape, kiwi, orange, plum, } \\
\text { banana, strawberry, mulberry, persimmon, etc. }\end{array}$ \\
\hline Sugar and soft drinks & $\begin{array}{l}\text { Soft drinks, sugar, chocolate, Gaz (an Iranian } \\
\text { confectionery made from nuts, tamarisk and } \\
\text { sugar), Sohan (an Iranian confectionery), } \\
\text { honey, jam, candy }\end{array}$ \\
\hline Nuts and legumes & $\begin{array}{l}\text { Almonds, pistachio, hazelnut, walnuts, seeds, } \\
\text { beans, lentil, dried pea, soya }\end{array}$ \\
\hline Salt & Salt \\
\hline
\end{tabular}

terms of daily (e.g. bread), weekly (e.g. rice and meat), monthly and yearly intakes. Reported food frequency was converted to daily intake (per gram) with respect to serving sizes ${ }^{(28)}$. Kitchen measuring cups were used to convert food servings. Food items were analysed for energy and nutrient contents using food composition tables (United States Department of Agriculture; USDA). Mixed foods were calculated according to their component ingredients.

\section{Food groups and identifying dietary patterns}

Food items were divided into twenty-five groups according to their composition and content (Table 1). The dietary patterns were extracted from questionnaires, based on the food intake data of the cases and controls. Extracted food groups were entered into the factor analysis, and dietary patterns were found according to principal component analysis. A change point in the scree plot was used to identify the number of patterns. With respect to inter-correlations among variables, factor loadings of $>0 \cdot 2$ were considered to determine the number of food groups in each dietary pattern. Dietary patterns were labelled based on their food items (Table 2).
Table 2. Factor loadings of food groups for Healthy and Unhealthy dietary patterns*

\begin{tabular}{|c|c|c|}
\hline Food groups & $\begin{array}{l}\text { Factor loadings: } \\
\text { 'Healthy' pattern }\end{array}$ & $\begin{array}{l}\text { Factor loadings: } \\
\text { 'Unhealthy' pattern }\end{array}$ \\
\hline $\begin{array}{l}\text { Red, organ meats and } \\
\text { processed meat }\end{array}$ & 0.566 & 0.664 \\
\hline Fish & 0.628 & 0.394 \\
\hline Poultry & 0.393 & 0.335 \\
\hline Eggs & 0.280 & \\
\hline Low-fat dairy products & 0.520 & \\
\hline High-fat dairy products & 0.228 & 0.518 \\
\hline Tea and coffee & & 0.275 \\
\hline Cabbage & 0.683 & \\
\hline Green leafy vegetables & 0.709 & \\
\hline $\begin{array}{l}\text { Orange and red } \\
\text { vegetables }\end{array}$ & 0.584 & \\
\hline Other vegetables & 0.729 & \\
\hline Baked potato & 0.401 & 0.243 \\
\hline French fries & & 0.459 \\
\hline Whole grains & 0.308 & \\
\hline Refined grains & & 0.214 \\
\hline Salted snacks & 0.475 & 0.656 \\
\hline Olives & 0.241 & \\
\hline Sweets and desserts & 0.440 & 0.716 \\
\hline Pickles & & 0.330 \\
\hline Hydrogenated oil & & 0.637 \\
\hline $\begin{array}{l}\text { Vegetable oil and } \\
\text { mayonnaise }\end{array}$ & 0.227 & \\
\hline Fruit and fruit juice & 0.604 & 0.470 \\
\hline Sugar and soft drinks & & 0.626 \\
\hline Nuts and legumes & 0.641 & \\
\hline Salt & & \\
\hline Explained variation (\%) & 25.08 & 8.56 \\
\hline
\end{tabular}

${ }^{*}$ Factor loadings $>0.2$ are presented. Kaiser-Meyer-Olkin measure of sampling adequacy $=0.83$. Bartlett's test of sphericity $=<0.001$

\section{Statistical analysis}

Kolmogorov-Smirnov test was applied to evaluate the normality of the data. Data analysis was performed using SPSS (version 16). Normally distributed quantitative variables, physical activity and qualitative variables were compared by independent $t$ test, Mann-Whitney test and $\chi^{2}$ test, respectively. As each participant received a factor score for each explored dietary pattern, we categorised the participants into tertiles of dietary pattern scores, so that each tertile contained approximately thirty individuals. Eventually, using logistic regression model with and without adjustment for different variables, the association of dietary patterns scores with BBD risk was assessed. The OR and 95\% CI were calculated for each dietary pattern tertile by logistic regression analysis. The relationship between the dietary patterns and BBD risk was adjusted for age, BMI, energy intake and confounders, with a $P$ value $<0.05$ in logistic regression. $P$ values $<0.05$ were considered significant.

\section{Results}

Table 3 provides general data for patients and healthy women. Mean age of cases and controls was 42.5 and 43.4 years, respectively, which was not significantly different. Mean age at first full-term pregnancy was significantly higher in cases 
Table 3. Characteristics of participants with benign breast disease and the controls

(Mean values and standard deviations; medians and interquartile ranges (IQR); numbers and percentages)

\begin{tabular}{|c|c|c|c|c|c|c|c|}
\hline & \multirow[b]{2}{*}{$n$} & \multicolumn{2}{|c|}{ Patients } & \multirow[b]{2}{*}{$n$} & \multicolumn{2}{|c|}{ Controls } & \multirow[b]{2}{*}{$P^{*}$} \\
\hline & & Mean & SD & & Mean & SD & \\
\hline Age (years) & 96 & $42 \cdot 5$ & $7 \cdot 8$ & 70 & 43.4 & $8 \cdot 3$ & 0.4 \\
\hline Education (years) & 96 & 11.6 & 3.9 & 70 & $11 \cdot 7$ & $4 \cdot 7$ & 0.9 \\
\hline Age at menarche (years) & 87 & $13 \cdot 3$ & 1.5 & 67 & $13 \cdot 4$ & 1.6 & 0.9 \\
\hline Age at first pregnancy (years) & 80 & 22.4 & $5 \cdot 3$ & 55 & $22 \cdot 0$ & 4.0 & 0.03 \\
\hline History of lactation (months) & 69 & $36 \cdot 5$ & $20 \cdot 2$ & 50 & $38 \cdot 7$ & $20 \cdot 2$ & 0.8 \\
\hline Weight $(\mathrm{kg})$ & 96 & 68.9 & 11.5 & 70 & $70 \cdot 6$ & $11 \cdot 1$ & 0.8 \\
\hline Height (cm) & 96 & 158.4 & $6 \cdot 2$ & 69 & $159 \cdot 1$ & $6 \cdot 2$ & 0.6 \\
\hline BMI $\left(\mathrm{kg} / \mathrm{m}^{2}\right)$ & 96 & 27.5 & $4 \cdot 2$ & 69 & $27 \cdot 9$ & 4.5 & 0.3 \\
\hline Waist circumference (cm) & 94 & 91.5 & $10 \cdot \overline{7}$ & 41 & 94.3 & 9.6 & 0.5 \\
\hline Total physical activity (MET-min/week) & 94 & & & 70 & & & 0.1 \\
\hline \multirow{3}{*}{$\begin{array}{l}\text { Median } \\
\text { IQR }\end{array}$} & & \multirow{2}{*}{\multicolumn{2}{|c|}{$\begin{array}{l}248 \cdot 63 \\
428 \cdot 38\end{array}$}} & & \multirow{2}{*}{\multicolumn{2}{|c|}{$\begin{array}{l}300 \cdot 50 \\
609 \cdot 07\end{array}$}} & \\
\hline & & & & & & & \\
\hline & & $n$ & $\%$ & & $n$ & $\%$ & \\
\hline \multicolumn{8}{|l|}{ Occupation } \\
\hline Employed & 96 & 20 & $20 \cdot 8$ & 70 & 30 & $42 \cdot 9$ & 0.002 \\
\hline Housekeeper & & 76 & $79 \cdot 2$ & & 40 & $57 \cdot 1$ & \\
\hline Marital status (married) & 96 & 83 & $86 \cdot 5$ & 70 & 62 & 88.6 & 0.7 \\
\hline \multicolumn{8}{|l|}{ Number of pregnancies } \\
\hline$\leq 2$ & 80 & 51 & $63 \cdot 8$ & 56 & 28 & $50 \cdot 0$ & 0.1 \\
\hline$>2$ & & 29 & $36 \cdot 2$ & & 28 & $50 \cdot 0$ & \\
\hline Menopause & 96 & 18 & $18 \cdot 8$ & 70 & 20 & 28.6 & 0.1 \\
\hline History of oestrogen therapy & 96 & 1 & 1.0 & 70 & 10 & $14 \cdot 3$ & 0.001 \\
\hline Oral contraceptive use & 96 & 39 & $40 \cdot 6$ & 70 & 27 & 38.6 & 0.8 \\
\hline Family history of breast disease or cancer & 96 & 17 & $17 \cdot 7$ & 70 & 18 & $25 \cdot 7$ & 0.2 \\
\hline Current use of dietary supplement & 96 & 45 & $46 \cdot 9$ & 70 & 29 & 41.4 & 0.5 \\
\hline Energy tertiles $(\mathrm{T})(\mathrm{kcal})$ & 96 & & 70 & & & & 0.2 \\
\hline $\mathrm{T} 1$ & & 33 & 34.4 & & 22 & 31.4 & \\
\hline T2 & & 36 & 37.5 & & 20 & 28.6 & \\
\hline T3 & & 27 & $28 \cdot 1$ & & 28 & $40 \cdot 0$ & \\
\hline \multicolumn{8}{|l|}{ Healthy food pattern tertiles } \\
\hline T1 & 96 & 35 & 36.5 & 70 & 17 & 24.3 & 0.09 \\
\hline T2 & & 32 & $33 \cdot 3$ & & 21 & 30.0 & \\
\hline T3 & & 29 & $30 \cdot 2$ & & 32 & $45 \cdot 7$ & \\
\hline \multicolumn{8}{|l|}{ Unhealthy food pattern tertiles } \\
\hline T1 & 96 & 32 & $33 \cdot 3$ & 70 & 26 & $37 \cdot 1$ & 0.6 \\
\hline $\mathrm{T} 2$ & & 35 & $36 \cdot 5$ & & 20 & 28.6 & \\
\hline T3 & & 29 & $30 \cdot 2$ & & 24 & $34 \cdot 3$ & \\
\hline
\end{tabular}

MET, metabolic equivalent task.

* Obtained by $\chi^{2}$ test for categorical variables and by $t$ test and Mann-Whitney $U$ test for continuous variables with normal and skewed distribution, respectively.

compared with healthy controls, whereas the percentage of employed women and those who had taken oestrogen was significantly higher in controls than in cases $(P<0 \cdot 05)$ (Table 3$)$. No other significant differences were observed. One of the patients was recognised with the history of tobacco use.

Two dietary patterns, entitled Healthy and Unhealthy, were obtained by factor analysis. Table 2 shows the factor loadings of food groups for the two dietary patterns, wherein the factor loadings $>0 \cdot 2$ were reported. Higher factor loading of a given food group indicates the greater contribution of that specific food group in the dietary pattern. Two dominant dietary patterns explained $33 \%$ of total variance. Healthy dietary pattern, with the variance of $25 \%$, consisted of fish, poultry, eggs, low-fat dairy products, cabbage, green leafy vegetables, yellow-orange vegetables, other types of vegetable, baked potato, legumes, nuts and seeds, whole grains, oil and mayonnaise, olives, fruits, dried fruits and fruit juices. Unhealthy dietary pattern, with the variance of $8 \%$, comprised red meats, organ and processed meats, high-fat dairy products, French fries, pickles (in vinegar or brine), refined grains, sweets and desserts, sugars and soda, tea and coffee, animal and solid fats and salted snacks. No significant differences were revealed when comparing frequency and tertile percentages of Healthy and Unhealthy dietary patterns in both case and control groups $(P>0.05)$. The percentages of patients in the first, second and third tertiles of Healthy dietary pattern were $36.5,33.3$ and $30.2 \%$, respectively, whereas the percentages of healthy women were $24.3,30.0$ and $45.7 \%$, respectively. Regarding Unhealthy dietary pattern, the percentages of patients in the first, second and third tertiles were $33.3,36.5$ and $30.2 \%$, respectively, whereas the percentages of healthy women were $37 \cdot 1,28 \cdot 6$ and $34 \cdot 3 \%$, respectively (Table 3 ).

The OR of BBD morbidity across tertiles of dietary pattern, before and after adjustment for confounding factors, is presented in four different models in Table 4. Before adjusting the confounders, subjects in the highest tertile had lower OR for 
Table 4. Benign breast diseases morbidity according to dietary patterns tertile (T) (Crude and adjusted odds ratios and $95 \%$ confidence intervals)

\begin{tabular}{|c|c|c|c|c|c|c|c|}
\hline & \multirow[b]{3}{*}{$n$} & \multicolumn{5}{|c|}{ Tertiles of dietary patterns } & \multirow[b]{3}{*}{$P_{\text {trend }} t$} \\
\hline & & \multirow{2}{*}{$\frac{\mathrm{T} 1}{\mathrm{OR}}$} & \multicolumn{2}{|c|}{$\mathrm{T} 2$} & \multicolumn{2}{|c|}{ T3 } & \\
\hline & & & OR & $95 \% \mathrm{Cl}$ & OR & $95 \% \mathrm{Cl}$ & \\
\hline \multicolumn{8}{|c|}{ Healthy food pattern } \\
\hline Model $1 \neq$ & 166 & 1.00 & 0.74 & $0.33,1.65 \S$ & 0.44 & $0.20,0.95^{\star}$ & 0.03 \\
\hline Model 2\| & 165 & 1.00 & 0.73 & $0.32,1.66$ & 0.44 & $0.20,0.99^{*}$ & 0.04 \\
\hline Model 3ब & 135 & 1.00 & 0.79 & $0.30,2.08$ & 0.42 & $0.17,1.06$ & 0.059 \\
\hline Model $4^{* *}$ & 134 & 1.00 & 1.06 & $0.38,2.94$ & 0.65 & $0.24,1.74$ & 0.3 \\
\hline \multicolumn{8}{|c|}{ Unhealthy food pattern } \\
\hline Model $1 \ddagger$ & 166 & 1.00 & 1.42 & $0.67,3.02$ & 0.98 & $0.46,2.08$ & 1.0 \\
\hline Model 2\| & 165 & 1.00 & 1.35 & $0.63,2.93$ & 0.95 & $0.42,2 \cdot 11$ & 0.9 \\
\hline Model 3ள & 135 & 1.00 & 1.86 & $0.75,4.62$ & 0.83 & $0.35,1.98$ & 0.7 \\
\hline Model $4^{\star *}$ & 134 & 1.00 & 1.98 & $0.76,5.15$ & 1.11 & $0.39,3.15$ & 0.7 \\
\hline
\end{tabular}

* Statistically significant.

† Numbers represented the $P$ value $_{\text {trend }}$ of OR in a row.

$\ddagger$ Model 1 was not adjusted.

$\S$ All OR and their corresponding $95 \% \mathrm{Cl}$ were calculated by performing logistic regression.

॥l Model 2 was adjusted for age (years), BMI $\left(\mathrm{kg} / \mathrm{m}^{2}\right)$ and energy intake (kcal).

I Model 3 was adjusted for age at first pregnancy (years), job status (employed/housekeeper) and history of oestrogen therapy (yes/no).

** Model 4 was adjusted for the variables included in the models 2 and 3 .

BBD compared with those in the lowest tertile (model 1: OR $0 \cdot 44 ; 95 \%$ CI $0 \cdot 2,0 \cdot 95)$. This relationship remained significant after adjusting for age, BMI and energy intake (model 2: OR 0.44; $95 \%$ CI 0.20, 0.99). After adjusting for age at first pregnancy, job status and history of oestrogen therapy, the association remained close to significance level (model 3: OR $0 \cdot 42 ; 95 \%$ CI $0.17,1.06$ ). However, after addition of age, BMI and energy intake to the previous model, the association did not remain significant (model 4: OR 0.65; $95 \%$ CI 0.24, 1.74).

No significant relationship was found between Unhealthy dietary pattern and BBD risk even after adjusting for potential confounders $\left(P_{\text {trend }}>0.05\right)$ (Table 4$)$.

\section{Discussion}

In the current study, the association between dietary patterns and BBD morbidity was investigated for the first time. Our results showed that the Healthy dietary pattern might be inversely associated with BBD, although after adjusting for some confounding variables a clear relationship was not observed. Besides, no significant relationship was found between the Unhealthy dietary pattern and BBD.

In line with the present findings, a study in Australia showed that higher consumption of poultry, sea foods, leafy and red-brown vegetables and fruits is associated with a lower risk of $\mathrm{BBD}^{(10)}$. In addition, Galvan-Portillo et al. ${ }^{(8)}$ reported that a higher fruit and dairy product intake could be related to a lower risk of BBD. Hislop et al. ${ }^{(9)}$ demonstrated a protective role against proliferative breast diseases with the intake of green vegetables. Consistent with these findings, in a case-control study, it was suggested that fruit and vegetable intake could be associated with a lower risk of fibrocystic breast disease, and the association was shown to be stronger in case of proliferative and atypical diseases, compared with non-proliferative conditions $^{(16)}$. However, in a clinical trial for $7 \cdot 7$ years, low-fat dietary pattern with decreased fat intake to $20 \%$ of total energy intake (decreased SFA intake to $<7 \%$ of total energy intake), increased fruit and vegetable intake to equal or more than five servings per $\mathrm{d}$ and increased cereal intake to six or more servings per $\mathrm{d}$ resulted in no-risk reduction of proliferative breast diseases ${ }^{(15)}$. The Healthy dietary pattern in our study consisted of food groups that might justify the reduction in BBD morbidity. Fruits and vegetables are rich in vitamins, antioxidants (e.g. vitamin C, vitamin $\mathrm{E}$ and $\beta$-carotene), minerals, fibre and other bioactive components. Antioxidants prevent DNA mutations and damage by eliminating free radicals ${ }^{(29)}$. Moreover, fruits and vegetables seem to contain ingredients with anti-proliferative effects on the breast epithelium $^{(16)}$. Fibres reduce circulatory levels of oestrogen and thus prevent breast cell proliferation ${ }^{(6)}$. These ingredients impede the reabsorption of oestrogen from the gastrointestinal tract ${ }^{(30)}$, leading to increased levels of oestrogen-binding globulin and lower bioavailability of these molecules ${ }^{(31)}$. Nuts are rich sources of unsaturated fatty acids and bioactive ingredients (such as high-quality plant proteins, fibre, minerals, tocopherols, phytosterols and phenolic compounds) with a huge impact on health ${ }^{(32)}$, and they can reduce benign and progressive breast diseases ${ }^{(6)}$. For instance, walnut contains bioactive compounds ( $\alpha$-linolenic acid and phytosterols) with anti-proliferative effects on breast epithelial cells ${ }^{(33)}$.

According to our data, a higher intake of Unhealthy dietary pattern in crude and adjusted models was not associated with BBD risk. In Shanghai cohort study, intake of red meats, eggs, fried foods, dairy products (except for non-proliferative diseases), rice and other cereals (except for proliferative diseases) was not related to breast fibrocystic conditions ${ }^{(16)}$. Ingram et al. ${ }^{(10)}$ showed that red meats, savoury foods (pizza, pie, stews, etc.) and starch are harmful for BBD. The consumption of fat from red meats was shown to be 
associated with proliferative forms of BBD in Canadian women ${ }^{(9)}$. We found no association between Unhealthy dietary pattern and BBD. This might stem from the recent transition in Iranian dietary patterns from traditional habits, which was similar to our Healthy dietary pattern, to new patterns resembling Western style or Unhealthy dietary pattern ${ }^{(34,35)}$. Therefore, it is possible that our participants consumed healthy foods in their childhood and adolescence and their habits changed to unhealthy diet in adulthood $^{(34)}$. However, risky time period for the development of BBD is unknown, but childhood and adolescent diet may have a role in BBD incidence in adulthood $^{(6,36)}$. Moreover, some food ingredients from Unhealthy dietary pattern might reduce the BBD risk. For example, although red meats and high-fat dairy products contain SFA, which are associated with increased risk of $\mathrm{BBD}^{(9,13)}$, retinol found in these foods reduces the $\operatorname{risk}^{(9,14)}$. Furthermore, organ meats contain nutrients such as folate and methionine functioning in DNA methylation and thus prevent carcinogenesis $^{(37)}$. Therefore, there could be a relation between folate intake and proliferative $\mathrm{BBD}$, as a precursor of breast cancer ${ }^{(38)}$.

The strength of the current study lies in selecting the patients who were diagnosed within the past month. This minimised the possible effect of the diagnosis on dietary patterns. In addition, it was a new research field on not only Iranian women but also in the globe. Nevertheless, our study had some limitations. First, by applying factor analysis in identifying the dietary patterns, food groups are categorised based on researcher's decision and previous literature, and thus changing the type of categorisation could lead to different results. Second, response errors in FFQ are possible. Under- or over-reporting of food consumption may result in errors in accurate estimation of consumed food ${ }^{(39)}$. However, in order to lower the bias, short-time interval between diagnosis and interview was used. Third, like all case-control studies, we could not determine the cause and effect relationship between the dietary patterns and BBD. Fourth, in spite of the high participation rate, samples may not be representative of the target population and selection bias is plausible. Regardless of these limitations, this study was the first attempt to examine the relationship between major dietary patterns and BBD.

For future studies, prospective designs are recommended to assess the relations between dietary patterns and BBD. In addition, larger sample size could be useful in studying dietary patterns with three subgroups of BBD separately. Also, the larger sample size may increase the chance to include more food groups to define dietary patterns in more detail.

According to the present findings, Healthy dietary pattern might be associated with a lower BBD risk; nevertheless, Unhealthy dietary pattern was not related to these diseases. However, this result should be interpreted with caution because of its limitations. Further studies are needed to confirm this finding.

\section{Acknowledgements}

The authors sincerely express their appreciation to the participants of this study.

This research project was supported by Tehran University of Medical Sciences, grant no. 93-454-111.
The authors' contributions are as follows: Z. S. M. and G. S. contributed to the study design and revised the manuscript. Z. T., F. K., S. K. and F. D. contributed to data collection and wrote the manuscript. M. Q. and F. K. contributed to data analysis and interpretation of the data. All authors listed approved the content of the submitted manuscript.

The authors have no conflicts of interest to declare.

\section{References}

1. Hunt KK, Green MC \& Buchholz TA (2012) Diseases of the breast. In Sabiston Textbook of Surgery, 19th ed. pp. 824-869 [CM Townsend, RD Beachamp, BM Evers and KL Mattox, editors]. St Louis, MO: WB Saunders.

2. Hartmann LC, Sellers TA, Frost MH, et al. (2005) Benign breast disease and the risk of breast cancer. NEngl J Med $\mathbf{3 5 3}$, 229-237.

3. Foulkes R \& Gateley CA (2010) Management of benign diseases of the breast. Surgery (Oxford) 28, 125-129.

4. Courtillot C, Plu-Bureau G, Binart N, et al. (2005) Benign breast diseases. J Mammary Gland Biol Neoplasia 10, 325-335.

5. Goehring C \& Morabia A (1997) Epidemiology of benign breast disease, with special attention to histologic types. Epidemiol Rev 19, 310-327.

6. Baer HJ, Schnitt SJ, Connolly JL, et al. (2003) Adolescent diet and incidence of proliferative benign breast disease. Cancer Epidemiol Biomarkers Prev 12, 1159-1167.

7. Baghurst PA \& Rohan TE (1995) Dietary fiber and risk of benign proliferative epithelial disorders of the breast. Int $J$ Cancer 63, 481-485.

8. Galvan-Portillo M, Anchez LT-S \& Lopez-Carrillo L (2002) Dietary and reproductive factors associated with benign breast disease in Mexican women. Nutr Cancer 43, 133-140.

9. Hislop TG, Band PR, Deschamps M, et al. (1990) Diet and histologic types of benign breast disease defined by subsequent risk of breast cancer. Am J Epidemiol 131, 263-270.

10. Ingram D, Nottage E \& Roberts T (1991) The role of diet in the development of breast cancer: a case-control study of patients with breast cancer, benign epithelial hyperplasia and fibrocystic disease of the breast. Br J Cancer 64, 187-191.

11. Li W, Ray RM, Lampe JW, et al. (2005) Dietary and other risk factors in women having fibrocystic breast conditions with and without concurrent breast cancer: a nested case-control study in Shanghai, China. Int J Cancer 115, 981-993.

12. London SJ, Stein EA, Henderson IC, et al. (1992) Carotenoids, retinol, and vitamin $\mathrm{E}$ and risk of proliferative benign breast disease and breast cancer. Cancer Causes Control 3, 503-512.

13. Lubin F, Wax Y, Ron E, et al. (1989) Nutritional factors associated with benign breast disease etiology: a casecontrol study. Am J Clin Nutr 50, 551-556.

14. Rohan TE, Cook MG, Potter JD, et al. (1990) A case-control study of diet and benign proliferative epithelial disorders of the breast. Cancer Res 50, 3176-3181.

15. Rohan TE, Negassa A, Caan B, et al. (2008) Low-fat dietary pattern and risk of benign proliferative breast disease: a randomized, controlled dietary modification trial. Cancer Prev Res 1, 275-284.

16. Wu C, Ray RM, Lin MG, et al. (2004) A case-control study of risk factors for fibrocystic breast conditions Shanghai Nutrition and breast disease study, China, 1995-2000. Am J Epidemiol 160, 945-960.

17. Frazier AL \& Rosenberg SM (2013) Preadolescent and adolescent risk factors for benign breast disease. I Adolesc Health 52, 36-40. 
18. Wu AH, Mimi CY, Tseng C-C, et al. (2009) Dietary patterns and breast cancer risk in Asian American women. Am J Clin Nutr 89, 1145-1154.

19. Buck K, Vrieling A, Flesch-Janys D, et al. (2011) Dietary patterns and the risk of postmenopausal breast cancer in a German case-control study. Cancer Causes Control 22, 273-282.

20. Edefonti V, Randi G, La Vecchia C, et al. (2009) Dietary patterns and breast cancer: a review with focus on methodological issues. Nutr Rev 67, 297-314.

21. Agurs-Collins T, Rosenberg L, Makambi K, et al. (2009) Dietary patterns and breast cancer risk in women participating in the Black Women's Health Study. Am J Clin Nutr 90, 621-628.

22. Fung TT, Hu FB, Holmes MD, et al. (2005) Dietary patterns and the risk of postmenopausal breast cancer. Int J Cancer 116, 116-121.

23. Männistö S, Dixon LB, Balder HF, et al. (2005) Dietary patterns and breast cancer risk: results from three cohort studies in the DIETSCAN project. Cancer Causes Control 16, 725-733.

24. Sieri S, Krogh V, Pala V, et al. (2004) Dietary patterns and risk of breast cancer in the ORDET cohort. Cancer Epidemiol Biomarkers Prev 13, 567-572.

25. Cottet V, Touvier M, Fournier A, et al. (2009) Postmenopausal breast cancer risk and dietary patterns in the E3N-EPIC prospective cohort study. Am J Epidemiol 170, 1257-1267.

26. Moghaddam MHB, Aghdam FB, Jafarabadi MA, et al. (2012) The Iranian Version of International Physical Activity Questionnaire (IPAQ) in Iran: content and construct validity, factor structure, internal consistency and stability. World Appl Sci 18, 1073-1080.

27. Mirmiran P, Hosseini Esfahani F, Mehrabi Y, et al. (2010) Reliability and relative validity of an FFQ for nutrients in the Tehran Lipid and Glucose Study. Public Health Nutr 13 , 654-662.
28. Ghafarpour M, Houshiar-Rad A \& Kianfar H (1999) The Manual for Housebold Measures, Cooking Yields Factors and Edible Portion of Foods, p. 49. Tehran: Nashre Olume Keshavarzy. [In Persian]

29. Weisburger J (1999) Mechanisms of action of antioxidants as exemplified in vegetables, tomatoes and tea. Food Chem Toxicol 37, 943-948.

30. Cohen L (1998) Dietary fiber and breast cancer. Anticancer Res 19, 3685-3688.

31. Goldin BR, Woods MN, Spiegelman DL, et al. (1994) The effect of dietary fat and fiber on serum estrogen concentrations in premenopausal women under controlled dietary conditions. Cancer 74, 1125-1131.

32. Ros E (2010) Health benefits of nut consumption. Nutrients 2 , 652-682.

33. Heuvel JPV, Belda BJ, Hannon DB, et al. (2012) Mechanistic examination of walnuts in prevention of breast cancer. Nutr Cancer 64, 1078-1086.

34. Ghassemi H, Harrison G \& Mohammad K (2002) An accelerated nutrition transition in Iran. Public Health Nutr 5, 149-155.

35. Galal O (2002) Nutrition-related health patterns in the Middle East. Asia Pacific J Clin Nutr 12, 337-343.

36. Ruder EH, Dorgan JF, Kranz S, et al. (2008) Examining breast cancer growth and lifestyle risk factors: early life, childhood, and adolescence. Clin Breast Cancer 8, 334-342.

37. Rohan TE, Jain MG, Howe GR, et al. (2000) Dietary folate consumption and breast cancer risk. J Natl Cancer Inst $\mathbf{9 2}$, 266-269.

38. Lakhani SR (1999) The transition from hyperplasia to invasive carcinoma of the breast. J Pathol 187, 272-278.

39. Kerver JM, Yang EJ, Bianchi L, et al. (2003) Dietary patterns associated with risk factors for cardiovascular disease in healthy US adults. Am J Clin Nutr 78, 1103-1110. 